\title{
ANALISA USAHA PETERNAKAN AYAM PETELUR SISTEM CLOSED HOUSE DI ROSSA FARM DESA KENDALREJO KECAMATAN SRENGAT KABUPATEN BLITAR
}

\author{
Rany Dwi Ramadhani \\ Fakultas Peternakan Universitas Islam Balitar, Blitar
}

\begin{abstract}
This research was conducted at laying hens Rossa Farm,Blitar regency. The objective of the research is to know how big the profit and feasibility level at laying hens Rossa Farm by using cage with closed house system in terms of economic analysis. Based on the calculation of profits in economic analysis of laying hens Rossa Farm value of $R / C$ ratio 2017 is 1.11. While the BEP results and prices for the year 2017 is 2,015,022.1 $\mathrm{kg}$ and Rp. 15.425,89,-. The margin of safety value of whole egg sales in 2017 that is 10,41\%. While the result of business feasibility calculation NVP value obtained from the farming business of laying hens Rossa Farm is Rp. 2.14.131.163,9,- and the IRR value obtained is 20,13\% or more than the 12\% discount rate, then this business is feasible to run.
\end{abstract}

Keywords : Closed house system, economic analysis.

\section{PENDAHULUAN}

Ayam petelur merupakan salah satu jenis ternak unggas yang cukup berkembang di Jawa Timur. Menurut data statistik jumlah rumah tangga usaha peternakan menurut wilayah dan jenis ternak tahun 2013 daerah di Provinsi Jawa Timur dengan jumlah usaha peternakan ayam ras petelur terbesar yaitu berada di Kabupaten Blitar dengan total 4.321 usaha peternakan ayam petelur.

Kabupaten Blitar sebagai daerah sentra telur sangat prospektif untuk kegiatan invenstasi dibidang peternakan. Populasi ternak ayam ras petelur yang terus berkembang mengakibatkatkan meningkatnya produksi telur.

Usaha peternakan ayam petelur merupakan usaha yang dapat menghasilkan perputaran modal yang cepat dan harga telurnya yang relatif murah sehingga mudah terjangkau oleh lapisan masyarakat. Namun demikian usaha peternakan ayam petelur tersebut masih sangat fluktuatif harganya. Sehingga usaha peternakan ayam petelur sangat rentan dalam perkembangannya, karena itu tidak sedikit usaha peternakan yang mengalami kerugian tersebut dan pada akhirnya menutup usahanya. Untuk mencapai keuntungan perlu adanya langkah upaya, salah satu diantaranya dengan mengetahui kelayakan suatu usaha peternakan ayam petelur.

Rossa Farm merupakan salah satu perusahaan yang bergerak dalam bidang usaha peternakan ayam ras petelur. Rossa Farm merupakan peternakan ayam petelur yang menggunakan tipe kandang sitem closed house pada periode layer.

Kandang tipe "closed house", merupakan tipe kandang yang tertutup dan mempunyai pengaturan ventilasi udara yang baik dengan bantuan control panel otomatis. Kandang tipe ini bertitik berat pada bagian modal awal seperti pembangunan kandang, pembelian alat control panel.

Berpijak dari keadaan di atas maka diperlukan suatu analisa ekonomi pada Rossa Farm untuk mengetahui seberapa besar tingkat keuntungan dan kelayakan dari usaha peternakan ayam petelur tersebut. 


\section{METODE PENELITIAN}

\section{Lokasi dan Waktu Kegiatan}

Pengambilan data dilaksanakan di peternakan ayam petelur Rossa Farm milik Bapak Drh. Nugroho Budiono M.Sc yang berada di Desa Kendalrejo Kecamatan Srengat Kabupaten Blitar pada bulan Maret - April 2017 dengan pertimbangan Rossa Farm merupakan salah satu perusahaan peternakan ayam petelur di Kabupaten Blitar yang sudah lama memulai usahanya dan tetap bertahan sampai sekarang.

\section{Populasi dan Sampel}

Populasi dalam penelitian ini adalah ayam petelur strain Isa/M dan Hisex Brown periode layer dengan total populasi 70.000 ekor milik Drh. Nugroho Budiono, M.Sc. dengan kandang sistem closed house yang terletak di Desa Kendalrejo Kecamatan Srengat Kabupaten Blitar.

\section{Metode Penelitian}

Penelitian ini akan dilakukan dengan menggunakan metoda deskriptif dan analisis, yaitu metode yang menggambarkan keadaan yang sebenarnya berdasarkan fakta-fakta atau kejadiankejadian dan data-data yang ada, kemudian data tersebut diolah, dianalisis dan diproses lebih lanjut dengan dasar teori-teori yang dipelajari dan dijadikan sebagai bahan penelitian dan pembahasan sehingga pada akhirnya menghasilkan suatu kesimpulan yang dapat digunakan sebagai dasar untuk memberikan saran terbaik.

\section{Metode Pengumpulan Data}

Metode pengumpulan data dalam penelitian ini adalah observasi dan wawancara. Data yang digunakan adalah data primer dan data skunder.

\section{Analisis Data}

Analisis ekonomi yang digunakan untuk melakukan perhitungan sebagai berikut:

a. Total biaya

$$
\mathrm{TC}=\mathrm{FC}+\mathrm{VC}
$$

Keterangan : $\mathrm{TC}=$ Biaya total

$$
\begin{aligned}
& \mathrm{FC}=\text { Biaya tetap } \\
& \mathrm{VC}=\text { Biaya tidak }
\end{aligned}
$$

b. Total penerimaan

$$
\begin{aligned}
& \text { TR = (p1 x Q) + ( } 2 \text { 2 } \times \mathrm{Q})+(\mathrm{p} 3 \times \mathrm{Q}) \\
& \text { Keterangan : TR }=\text { Total revenue } \\
& \mathrm{p} 1=\text { Harga } / \mathrm{kg} \text { telur } \\
& \mathrm{p} 2=\text { Harga } / \mathrm{kg} \text { ayam afkir } \\
& \mathrm{p} 3=\text { Harga } / \text { hasil samping }
\end{aligned}
$$




$$
\mathrm{Q}=\text { Jumlah produksi }
$$

c. Pendapatan

$$
\begin{aligned}
& \Pi=\mathrm{TR}-\mathrm{TC} \\
& \text { Keterangan : } \Pi=\text { Pendapatan } \\
& \mathrm{TR}=\text { Total penerimaan } \\
& \mathrm{TC}=\text { Total biaya }
\end{aligned}
$$

d. $\mathrm{R} / \mathrm{C}$ rasio

$$
\mathrm{a}=\frac{\text { TR }}{\text { TC }}
$$

Keterangan : $\quad a=\mathrm{R} / \mathrm{C}$ rasio

$$
\begin{aligned}
& \mathrm{TR}=\text { Total penerimaan } \\
& \mathrm{TC}=\text { Total biaya }
\end{aligned}
$$

Kriteria penilaian $\mathrm{R} / \mathrm{C}$ rasio sebagai berikut :

$>\quad \mathrm{R} / \mathrm{C}$ rasio $>1$, usaha peternakan ayam petelur layak dikembangkan.

$>\mathrm{R} / \mathrm{C}$ rasio $=1$, usaha peternakan ayam petelur tersebut tidak untung tidak rugi (impas).

$>\mathrm{R} / \mathrm{C}$ rasio $<1$, usaha peternakan ayam petelur tidak layak dikembangkan.

e. Break even point (BEP)

$$
\mathrm{BEP}(\text { harga })=\frac{\text { Biaya produksi total }}{\text { Hasil produksi }}
$$

f. Margin Of Safety(MOS)

$$
\text { MOS }=\frac{\text { PENJUALAN }- \text { PENJUALAN BEP }}{\text { PENJUALAN }} \times 100 \%
$$

\section{g. Net Present Value(NPV)}

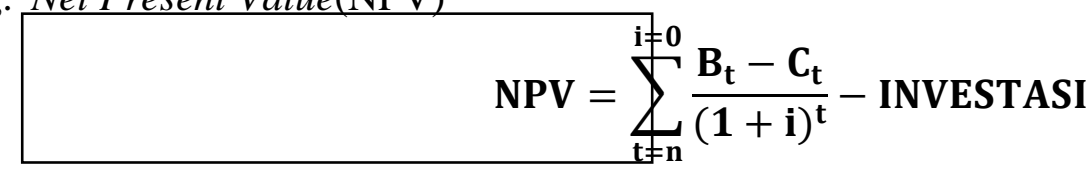

$$
\text { Keterangan : } \begin{aligned}
\mathrm{B} & =\text { Benefit (manfaat) } \\
\mathrm{C} & =\text { Cost } \text { (biaya) } \\
\mathrm{i} & =\text { Discount factor }(\mathrm{DF}) \\
\mathrm{t} & =\text { Tahun }
\end{aligned}
$$

Adapun kriteria penilaian NPV adalah sebagai berikut :

1. Jika NPV $>0$. maka usaha yang dijalankan layak untuk dilaksanakan. 
2. Jika NPV < 0. maka usaha yang dijalankan tidak layak untuk dilaksanakan.

3. Jika NPV $=0$. maka nilai perusahaan tetap dimana perusahaan tidak rugi dan tidak untung.

\section{h. Internal Rate of Return(IRR)}

$$
\operatorname{IRR}=\mathbf{i}+\frac{\mathrm{NPV}_{1}}{\mathrm{NPV}_{\mathbf{1}}-\mathrm{NPV}_{2}}\left(\mathbf{i}_{1}-\mathbf{i}_{2}\right)
$$

Keterangan:

$\mathrm{i}_{1} \quad=$ Tingkat discount rate yang menghasilkan NPV

$\mathrm{i}_{2} \quad=$ Tingkat discount rate yang menghasilkan $\mathrm{NPV}_{2}$

$\mathrm{NPV}_{1}=\mathrm{NPV}$ bernilai positif mendekati nilai nol (0)

$\mathrm{NPV}_{2}=\mathrm{NPV}$ bernilai negative mendekatinol (0)

Apabila IRR = tingkat discount rate maka usaha tidak mendapatkan untung maupun rugi, tetapi jika IRR < tingkat discount rate maka usaha tersebut tidak layak diusahakan, sedangkan apabila IRR > tingkat discount rate maka usaha tersebut layak untuk diusahakan.

\section{HASIL DAN PEMBAHASAN}

\section{Usaha Peternakan Ayam Petelur Rossa Farm}

Rossa Farm merupakan perusahaan peternakan ayam petelur mulai dari periode starter hingga periode layer dengan lokasi kandang yang terpisah. Lokasi kandang periode layer tersebut berada di desa Kendalrejo, kecamatan Srengat kabupaten Blitar. Usaha peternakan ayam petelur Rossa Farm mulai berdiri pada tahun 2000 dan didirikan oleh Drh. Nugroho Budiono, M. Sc. Awal mula pemeliharaan ayam periode layer di Rossa Farm menggunakan kandang sistem terbuka. Namun karena produksi tidak bagus serta permintaan akan telur ayam semakin meningkat maka pada tahun 2007 sistem kandang diubah dengan sistem closed house, yaitu dengan menggunakan fan, cooling system dan tirai/penutup dinding samping.

Penggunaan tipe ini dikarenakan daerah lokasi kandang yang panas sehingga jika menggunakan kandang sistem terbuka hasil produksinya kurang bagus. Menurut Rasyaf (2012), tipe kandang yang ideal untuk peternakan di daerah Indonesia adalah tipe kandang tertutup (closed house) baik sistem kandang tertutup dengan sistem cooling pad maupun kandang sistem tertutup dengan sistem tunnel.

Sistem closed house memiliki kelebihan seperti kontrol suhu, kelembaban dan kecepatan angin, serta meningkatkan performa dan kenyamanan ayam sehingga meningkatkan kualitas dan kuantitas produksi. Seperti yang diutarakan Ustomo ( 2016), kandang closed house atau kandang tertutup mampu meminimalkan pengaruh buruk di dalam dan di luar lingkungan kandang serta dapat meningkatkan produktivitas ayam. Adapun tujuan membangun kandang closed house yaitu sebagai berikut :

a. Menyediakan udara yang sehat bagi ternak ( sistem ventilasi yang baik) yaitu udara banyak mengandung oksigen dan mengeluarkan sesegera mungkin gas - gas berbahaya seperti karbondioksida dan ammonia.

b. Menyediakan suhu dan kelembapan yang ideal serta nyaman bagi ternak.

c. Meminimumkan tingkat stress pada ternak.

Untuk menyediakan iklim yang kondusif bagi ternak dapat dilakukan dengan cara mengeluarkan panas dari kandang yang dihasilkan dari tubuh ayam dengan lingkungan luar, menurunkan suhu udara yang masuk serta mengatur kelembaban yang sesuai. Untuk 
menciptakan iklim yang sejuk dan nyaman maka bagi ayam harus dikondisikan chilling effect (angin berembus), alat yang digunakan seperti kipas angin (blower).

Peternakan ayam petelur Rossa Farm di desa Kendalrejo kecamatan Srengat didirikan diatas lahan seluas $20.000 \mathrm{~m}^{2}$, terdiri dari 3 lokasi kandang produksi dengan total kapasitas maksimal 70.000 ekor, 1 unit kantor, 1 unit gudang telur dan 1 unit gudang pakan. Lokasi perkandangan dibagi menjadi 3 kandang. Strain ayam yang dipelihara adalah Hisex Brown dan Isa Brown. Ayam yang dipelihara pada periode produksi adalah pullet umur 13 minggu. Umur ayam yang dipelihara dalam usaha peternakan ayam petelur sistem closed house di Rossa Farm dibuat satu lokasi dengan satu umur ayam yang seragam, sehingga terdapat tiga umur ayam yang berbeda sehingga produksi telur dapat terus berkesinambungan. Dalam pengelolaan usaha peternakan Rossa Farm, terdapat 20 karyawan yang semuanya memiliki tugas dan kewajibanya masing masing.

\section{Arus Pengeluaran (Outflow)}

Komponen biaya dikelompokan menjadi dua bagian, yaitu investasi dan biaya produksi. Biaya investasi adalah biaya yang harus dikeluarkan pada awal tahun usaha atau pada saat usaha telah berlangsung untuk mendapatkan faktor - faktor produksi yang digunakan dalam proses produksi. Biaya produksi adalah sejumlah biaya yang dikeluarkan agar proses dapat berlangsung.

\section{Modal Investasi}

Modal investasi adalah biaya yang dikeluarkan satu kali dalam satu periode proses produksi untuk memperoleh berapa kali manfaat secara ekonomis yang dikeluarkan pada awal kegiatan dan jumlahnya cukup besar. Rincian modal investasi dapat dilihat pada tabel 1 .

Tabel 1. Tabel modal investasi usaha peternakan Rossa Farm

\begin{tabular}{|r|l|r|r|r|r|r|}
\hline No & \multicolumn{1}{|c|}{ Uraian } & \multicolumn{1}{|c|}{ Volume } & \multicolumn{1}{c|}{ Satuan } & \multicolumn{1}{c|}{$\begin{array}{r}\text { Harga satuan } \\
\text { (Rp) }\end{array}$} & Jumlah (Rp) & \% \\
\hline I & INVESTASI & & & & & \\
\hline 1 & Tanah & 20.000 & $\mathrm{~m}^{2}$ & 200.000 & 4.000 .000 .000 & $39.17 \%$ \\
\hline 2 & Kandang & 3 & per ekor & 60.000 & 4.200 .000 .000 & $41.13 \%$ \\
\hline 3 & $\begin{array}{l}\text { Tempat Pakan dan } \\
\text { Minum }\end{array}$ & & & & \\
\hline a. & Tempat Pakan & 1.500 & $\mathrm{~m}$ & 20.000 & 30.000 .000 & $0.29 \%$ \\
\hline & Paralon & 25 & unit & 2.800 .000 & 70.000 .000 & $0.69 \%$ \\
\hline & Feeder Semi Otomatis & 4.750 & buah & 6.300 & 55.125 .000 & $0.54 \%$ \\
\hline d. & Niple & 3.000 & $\mathrm{~m}$ & 15.000 & 60.000 .000 & $0.59 \%$ \\
\hline 4 & Terpal & 300 & lembar & 600.000 & 180.000 .000 & $1.76 \%$ \\
\hline 5 & Cooling Pad & unit & 10.000 .000 & 30.000 .000 & $0.29 \%$ \\
\hline 6 & $\begin{array}{l}\text { Tandon Air(beserta } \\
\text { instalasi) }\end{array}$ & 60 & unit & 9.000 .000 & 540.000 .000 & $5.29 \%$ \\
\hline 7 & Exhaust Fan & & & & \\
\hline
\end{tabular}




\begin{tabular}{|c|c|c|c|c|c|c|}
\hline 8 & $\begin{array}{l}\text { Peralatan dan } \\
\text { Perlengkapan Kandang }\end{array}$ & & & & & \\
\hline \multirow[t]{3}{*}{ a. } & Genset & & & & & \\
\hline & Ukuran besar (150 KVA) & 1 & unit & 150.000 .000 & 150.000 .000 & $1.47 \%$ \\
\hline & Ukuran kecil (80 KVA) & 1 & unit & 80.000 .000 & 80.000 .000 & $0.78 \%$ \\
\hline b. & Timbangan duduk & 3 & buah & 2.000 .000 & 6.000 .000 & $0.06 \%$ \\
\hline 9 & Mesin Pemecah Jagun & 1 & unit & 18.000 .000 & 18.000 .000 & $0.18 \%$ \\
\hline 10 & $\begin{array}{l}\text { Mesin Pencampur Pakan } \\
:\end{array}$ & & & & & \\
\hline a. & Mesin Vertikal & 1 & unit & 25.000 .000 & 25.000 .000 & $0.24 \%$ \\
\hline b. & Mesin Horizontal & 1 & unit & 52.000 .000 & 52.000 .000 & $0.51 \%$ \\
\hline 11 & Mesin Pencampur Obat & 1 & unit & 16.000 .000 & 16.000 .000 & $0.16 \%$ \\
\hline \multirow[t]{2}{*}{12} & $\begin{array}{l}\text { Bangunan Gudang } \\
\text { Pakan. Gudang Telur dan } \\
\text { Kantor }\end{array}$ & 3 & unit & & 700.000 .000 & $6.85 \%$ \\
\hline & TOTAL & & & & 10.212.125.000 & $100.0 \%$ \\
\hline
\end{tabular}

Sumber : Data primer yang diolah (2017).

\section{Biaya Produksi}

Biaya produksi yang digunakan peternakan Rossa Farm meliputi biaya tetap dan biaya tidak tetap. Biaya tetap yang dikeluarkan peternakan Rossa Farm antara lain biaya penyusutan, bunga modal, PBB, dan biaya sewa tanah. Bunga modalnya sebesar $12 \%$ pertahun. Biaya tidak tetap yang dikeluarkan peternakan Rossa Farm meliputi biaya pakan,gaji tenaga kerja, listrik, vaksin dan obat, hingga biaya perbaikan dan pemasaran.

Tabel 2. Total biaya produksi peternakan ayam petelur Rossa Farm selama satu tahun 2016.

\begin{tabular}{|c|l|r|c|}
\hline No & \multicolumn{1}{|c|}{ Jenis } & \multicolumn{1}{c|}{ Jumlah } & \multicolumn{1}{c|}{$\%$} \\
\hline I & BIAYA TETAP & & \\
\hline 1 & Penyusutan & & \\
\hline a. & Kandang & 525.000 .000 & $1,59 \%$ \\
\hline b. & Peralatan Makan dan Minum : & \\
\hline - & Paralon & 3.333 .333 & $0,01 \%$ \\
\hline - & Feeder Semi Otomatis & 11.666 .667 & $0,04 \%$ \\
\hline - & Niple & 11.025 .000 & $0,03 \%$ \\
\hline c. & Terpal & 20.000 .000 & $0,06 \%$ \\
\hline d. & Cooling Pad & 36.000 .000 & $0,11 \%$ \\
\hline e. & Tandon Air & 3.333 .333 & $0,01 \%$ \\
\hline f. & Exhaust Fan & 135.000 .000 & $0,41 \%$ \\
\hline g. & Peralatan dan Perlengkapan Kandang : & & \\
\hline & Genset & & \\
\hline & Ukuran Besar (150 KVA) & 50.000 .000 & $0,15 \%$ \\
\hline & Ukuran Kecil (80 KVA) & 26.666 .667 & $0,08 \%$ \\
\hline & Timbangan duduk & 2.000 .000 & $0,006 \%$ \\
\hline
\end{tabular}




\begin{tabular}{|c|l|r|r|}
\hline h. & Mesin Pemecah Jagun & 2.000 .000 & $0,006 \%$ \\
\hline i. & Mesin Pencampur Pakan : & \\
\hline j. & Mesin Vertical & 2.777 .778 & $0,01 \%$ \\
\hline k. & Mesin Horizontal & 5.777 .778 & $0,02 \%$ \\
\hline l. & Mesin Pencampur Obat & 1.777 .778 & $0,005 \%$ \\
\hline m. & Bangunan Gudang Pakan, Gudang Telur & 77.777 .778 & $0,24 \%$ \\
\hline dan Kantor & Gaji Tenaga Kerja : & & \\
\hline a. & Supervisor dan Dokter Hewan & 72.000 .000 & $0,22 \%$ \\
\hline b. & Anak Kandang (> 5 tahun kerja) & 86.400 .000 & $0,26 \%$ \\
\hline c. & Anak Kandang (<5 tahun kerja) & 159.600 .000 & $0,48 \%$ \\
\hline 3. & Sewa tanah & 72.727 .200 & $0,22 \%$ \\
\hline 4. & PBB & 10.800 .000 & $0,03 \%$ \\
\hline 5. & Bunga modal & 1.225 .455 .000 & $3,71 \%$ \\
\hline & TOTAL BIAYA TETAP & $\mathbf{2 . 5 4 1 . 1 1 8 . 3 1 2}$ & $\mathbf{7 , 7 0 \%}$ \\
\hline
\end{tabular}

Sumber: Data primer yang diolah (2017)

\begin{tabular}{|l|l|r|r|}
\hline NO & \multicolumn{1}{|c|}{ JENIS } & \multicolumn{1}{c|}{ JUMLAH } & \multicolumn{1}{c|}{$\%$} \\
\hline II & BIAYA TIDAK TETAP & & \\
\hline 1. & Pakan & 23.512 .895 .000 & $71 \%$ \\
\hline 2. & Pullet Ayam Petelur & 1.197 .690 .000 & $3,63 \%$ \\
\hline 3. & Egg Tray & 64.800 .000 & $0,20 \%$ \\
\hline 4. & VOVD & 587.043 .000 & $1,78 \%$ \\
\hline 5. & Listrik & 396.000 .000 & $1,20 \%$ \\
\hline 6. & Biaya Perbaikan & 2.808 .350 .000 & $8,51 \%$ \\
\hline 7. & Biaya Pemasaran & 1.911 .690 .630 & $5,79 \%$ \\
\hline & TOTAL BIAYA TIDAK TETAP & 30.478 .468 .630 & $\mathbf{9 2 , 3 0 \%}$ \\
\hline & TOTAL BIAYA PRODUKSI & $\mathbf{3 3 . 0 1 9 . 5 8 6 . 9 4 2}$ & $\mathbf{1 0 0 , 0 \%}$ \\
\hline
\end{tabular}

Sumber: Data primer yang diolah (2017)

Tabel 2 menunjukan biaya pakan merupakan biaya terbesar produksi yaitu

Rp. $23,512,895,000$,- atau $71 \%$ dari total biaya. Sedangkan biaya tetap hanya Rp. 2.541.118.312 atau berkisar 7,70\% dari total biaya produksi. Sedangkan biaya penyusutan kandang dan mesin - mesin hanya berkisar dibawah $2 \%$ dari total biaya produksi.

Biaya pemasaran merupakan biaya yang digunakan untuk memasarkan produk telur utuh, dimana telur tersebut didistribusikan atau dikirim ke daerah Jakarta setiap dua kali dalam 1 bulan yang nantinya akan dipasarkan ke swalayan atau pasar modern. Biaya pemasaran terdiri dari biaya transportasi,biaya kemasan telur dan biaya lain - lain, sehingga biaya pemasaran setiap $1 \mathrm{Kg}$ telurnya sebesar Rp. 1.100,- diamana dalam satu tahun Rossa Farm memasarkan telur sebanyak $2.124 .100,7 \mathrm{Kg}$. Maka dalam satu tahun total biaya pemasaran memerlukan biaya sebesar Rp. 1.911.690.630,- atau sebesar 5,79\%. 
Biaya yang cukup besar dalam biaya tidak tetap adalah biaya perbaikan. Hal ini dikarenakan terjadi penyusutan atau penurunan fungsi aktiva. Menurut Mahyuddin (2013), aktiva memiliki dua jenis umur, yaitu umur fisik dan umur fungsional. Suatu aktiva dikatakan masih memiliki umur fisik apabila secara fisik aktiva tersebut masih dalam kondisi baik (walaupun mungkin sudah menurun fungsinya). Suatu aktiva masih memiliki umur fungsional apabila aktiva tersebut masih member konstribusi bagi perusahaan. Beberapa contoh aktiva dalam usaha peternakan ayam petelur Rossa Farm adalah kandang, cooling pad, exhaust fan, gudang pakan, gudang telur, mesin pemecah jagung, mesin pencampur pakan dan masih banyak lagi.

Walaupun aktiva - aktiva tersebut sudah menurun fungsinya namun aktiva tersebut masih memiliki umur fungsional. Sehingga cara mengatasinya yaitu dengan memperbaiki aktiva yang masih memiliki umur fungsional dan mengganti aktiva yang sudah tidak berfungi. Biaya perbaikan dalam satu tahun yaitu sebesar Rp. 2,808,350,000,- atau 8,51\% dari total biaya produksi.

\section{Arus Penerimaan (Inflow)}

Penerimaan adalah sesuatu yang dapat meningkatkan bisnis. Arus manfaat usaha ini adalah penerimaan dari hasil penjualan telur utuh, telur afkir, ayam afkir, serta kotoran.

\section{Penerimaan}

Menurut Asnawi (2009), penerimaan ayam ras petelur diperoleh setelah hasil produksi dijual yaitu bersumber dari penjualan telur, ayam afkir dan kotoran ayam. Rossa Farm mendapatkan penerimaan daripenjualan telur (telur utuh, telur retak dan telur cangkang putih), penjualan ayam afkir dan penjualan pupuk kandang. Harga penjualan telur utuh tertinggi dan terendah dari bulan Januari tahun 2015 hingga April tahun 2017 yaitu Rp. 19.800,-/Kg pada bulan Januari tahun 2016, sedangkan harga penjualan terendah yaitu Rp. 13.500,-/Kg pada bulan Maret tahun 2015. Untuk telur afkir (telur retak, telur putih dan telur sortir) akan dijual kepedagang khusus telur afkir dengan harga 20\% dari harga telur utuh. Ayam yang telah diafkir akan dijual langung kepedagang khusus dengan harga Rp. 15.000/Kg. Sedangkan penjualan kotoran dilakukan satu tahun sekali pada saat ayam afkir dengan harga Rp. 180 untuk setiap kilogramnya.

Tabel 3. Total produksi usaha peternakan ayam petelur Rossa Farm tahun 2015 - 2017.

\begin{tabular}{|c|l|r|r|r|}
\hline No & \multicolumn{1}{|c|}{ Jenis } & \multicolumn{1}{c|}{ Tahun 2015 } & \multicolumn{1}{c|}{ Tahun 2016 } & \multicolumn{1}{c|}{ Tahun 2017 } \\
\hline 1. & Telur utuh $(\mathrm{Kg})$ & $2.005 .093,6$ & $2.124 .100,7$ & $2.168 .392,0$ \\
\hline 2. & Telur afkir $(\mathrm{Kg})$ & $24.885,7$ & $26.885,7$ & $28.720,2$ \\
\hline 3. & Ayam afkir $(\mathrm{ekor})$ & 28.540 & 20.001 & 27.977 \\
\hline 4. & Kotoran ayam $(\mathrm{Kg})$ & $28.840,8$ & $54.334,9$ & $38.840,8$ \\
\hline
\end{tabular}

Sumber: Data primer yang diolah (2017)

Grafik 1. Penerimaan usaha peternakan ayam petelur Rossa Farm tahun 2015 - 2017 


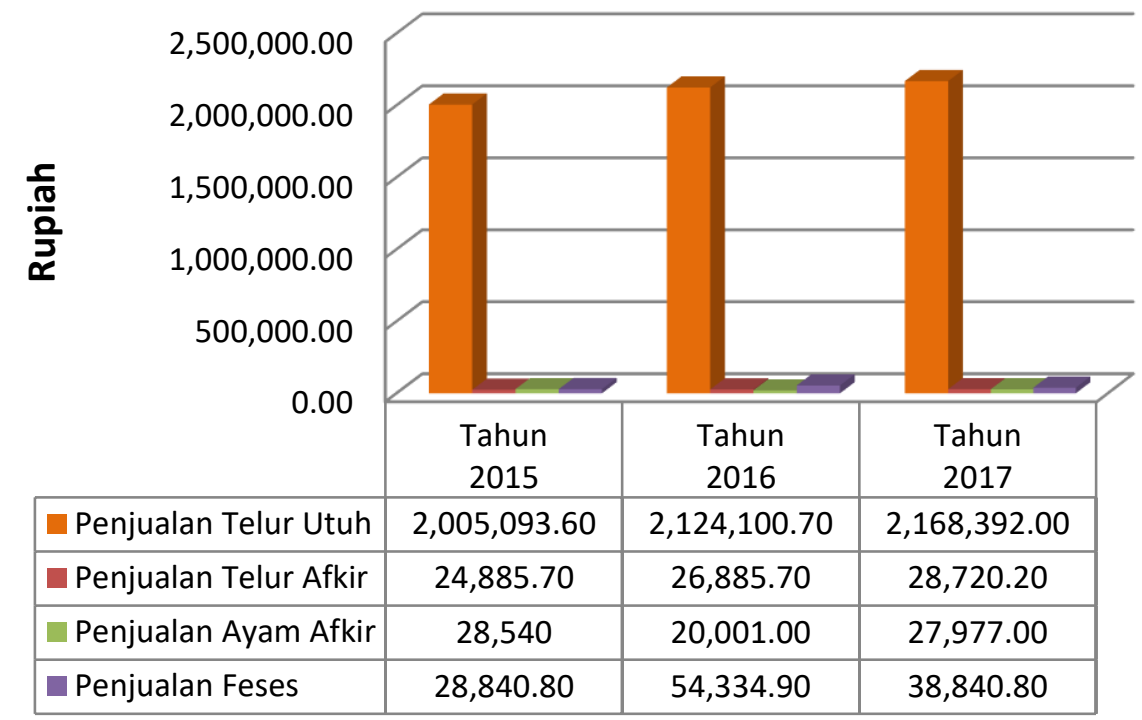

Sumber: Data primer yang diolah (2017)

Tabel 3 menunjukan hasil produksi usaha ayam petelur Rossa Farm mulai dari produksi telur, ayam afkir, hingga kotoran ayam dalam kurun waktu tahun 2015 hingga tahun 2017. Dari tahun 2015 hingga tahun 2017 produksi telur khususnya telur utuh meningkat $0.02-0.05 \%$.

Sedangkan pada grafik 1 menunjukan hasil penerimaan usaha peternakan ayam petelur Rossa Farm. Total penerimaan usaha peternakan ayam petelur Rossa Farm yaitu Rp. 34.270.925.,014,-- pada tahun 2015, Rp. 36.265.868.025,-, sedangkan pada tahun 2017 yaitu Rp. 37.223.102.800,-.

\section{Analisis Laba Dan Rugi}

Perhitungan laba dan rugi digunakan untuk melihat apakah usaha peternakan ayam petelur Rossa Farm menguntungkan atau tidak.

\section{Pendapatan}

Keuntungan atau pendapatan pada usaha peternakan ayam petelur merupakan selisih antara penerimaan total dengan biaya total produksi yang dikeluarkan. Jika selisih tersebut bernilai positif maka dapat dikatakan bahwa usaha peternakan ayam petelur itu untung sedangkan jika diperoleh nilai yang negative berarti usaha tersebut mengalami kerugian (Asnawi, 2009).

Tabel 4. Total penerimaan dan biaya produksi usaha peternakan ayam petelur Rossa Farm.

\begin{tabular}{|l|l|l|l|}
\hline \multicolumn{1}{|c|}{ Uraian } & Tahun 2015 & Tahun 2016 & Tahun 2017 \\
\hline Total Penerimaan & 34.270 .925 .014 & 36.265 .868 .025 & 37.233 .102 .800 \\
\hline Total Biaya Produksi & 30.375 .644 .312 & 33.019 .586 .942 & 33.449 .367 .132 \\
\hline
\end{tabular}

Sumber: Data primer yang diolah (2017)

Grafik 2. Pendapatan usaha peternakan ayam petelur Rossa Farm Tahun 2015 - tahun 2017. 


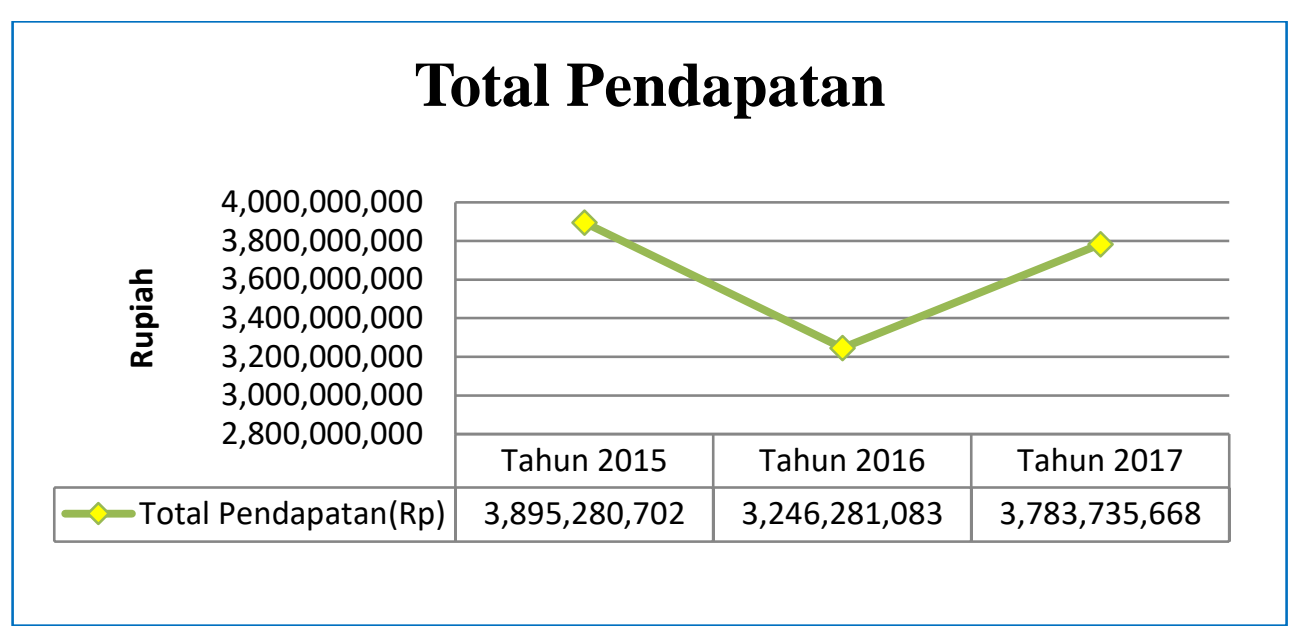

Sumber: Data primer yang diolah (2017)

Tabel 4 menunjukan total penerimaan dan total biaya produksi peternakan Rossa Farm pada tahun 2015 - 2017. Pada tahun 2015 biaya produksi mencapai Rp. 30.375.644.312,- dengan total penerimaan yang diterima yaitu Rp. 34.270.925.014.

Grafik 2 menunjukan total pendapatan Rossa Farm. Pendapatan yang diterima pada tahun 2015 mencapai Rp. 3.895.280.702,-. Namun pendapatan Rossa Farm mengalami penurunan pada tahun 2016. Pendapatan yang dihasilkan pada tahun 2016 yaitu Rp. 3,246,281,083,-. Hal ini bukan disebabkan oleh hasil produksi, namun karena harga telur pada saat itu fluktuatif. Harga telur utuh terendah pada tahun 2016 mencapai Rp. 14.500,--

\section{Rasio Penerimaan Atas Biaya (R/C ratio)}

Pendapatan usaha yang besar tidak selalu mencerminkan tingkat efesiensi usaha yang tinggi. Guna mengetahui efesiensi usaha tersebut dapat digunakan analisis $\mathrm{R} / \mathrm{C}$ ratio. $\mathrm{R} / \mathrm{C}$ ratio merupakan singkatan dari Return Cost Ratio, atau perbadingan antara penerimaan dan biaya. Suatu usaha dapat dinyatakan layak atau masih dalam tingkat efesiensi apabila nilai $\mathrm{R} / \mathrm{C}$ ratio lebih dari satu, yang artinya nilai penerimaan sama lebih besar dari total biaya. Maka semakin besar nilai $\mathrm{R} / \mathrm{C}$ ratio maka semakin besar pula tingkat efisiensi suatu perusahaan.

Tabel 5. Nilai R/C ratio usaha peternakan ayam petelur Rossa Farm Tahun 2015 - 2017

\begin{tabular}{|l|r|r|r|}
\hline \multicolumn{1}{|c|}{ Uraian } & Tahun 2015 & Tahun 2016 & \multicolumn{1}{c|}{ Tahun 2017 } \\
\hline Total Penerimaan & 34.270 .925 .014 & 36.265 .868 .025 & 37.233 .102 .800 \\
\hline Total Biaya Produksi & 30.375 .644 .312 & 33.019 .586 .942 & 33.449 .367 .132 \\
\hline R/C ratio & $\mathbf{1 , 1 3}$ & $\mathbf{1 , 1 0}$ & $\mathbf{1 , 1 1}$ \\
\hline
\end{tabular}

Sumber : Data primer yang diolah (2017)

Tabel 5 menunjukan bahwa nilai R/C ratio di usaha peternakan ayam petelur Rossa Farm pada tahun 2015 - 2017 bernilai lebih dari satu. Dari tahun ke tahun nilai R/C ratio terus meningkat. Menurut Soekartawi yang dikutip oleh Candra (2012), menyatakan bahwa untuk nilai $\mathrm{R} / \mathrm{C}$ ratio lebih dari 1 maka usaha tersebut dinyatakan menguntungkan atau layak untuk dikembangkan. Nilai R/C ratio pada tahun 2016 sebesar 1,10 maka dapat diartikan bahwa setiap penggunaan biaya produksi peternakan ayam petelur Rossa Farm sebesar Rp. 1.000.000,- akan memperoleh penerimaan sebesar Rp. 1.100.000,-. 


\section{Break Even Point (BEP)}

Break even poin adalah suatu keadaan dimana suatu usaha tidak memperoleh laba dan tidak menderita rugi (penghasilan sama dengan total biaya)(Mandala, 2014). Analisa BEP diperlukan untuk mengetahui hubungan antara volume produksi, volume penjualan, harga jual, biaya produksi dan biaya lainya baik yang bersifat tetap maupun variabel, dan laba atau rugi.

Menurut Munawir yang dikutip oleh Candra (2012), bahwa analisa BEP tidak hanya semata - mata untuk mengetahui keadaan perusahaan yang break even saja, akan tetapi analisa BEP mampu memberikan informasi mengenai berbagai tingkat volume penjualan, serta hubungan dengan kemungkinan memperoleh laba menurut tingkat penjualan yang bersangkutan.

Tabel 6. BEP harga telur utuh dan BEP hasil telur utuh usaha peternakan ayam petelur Rossa Farm

\begin{tabular}{|l|r|r|r|}
\hline \multicolumn{1}{|c|}{ Keterangan } & \multicolumn{1}{c|}{ Tahun 2015 } & \multicolumn{1}{c|}{ Tahun 2016 } & \multicolumn{1}{c|}{$\mathbf{2 0 1 7}$} \\
\hline Biaya Produksi (Rp) & 30.375 .644 .312 & 33.019 .586 .942 & 33.449 .367 .132 \\
\hline $\begin{array}{l}\text { Rata-rata harga jual per kg utuh } \\
(\mathrm{Rp})\end{array}$ & 16.475 & 16.629 & 16.600 \\
\hline Produksi telur utuh $(\mathrm{kg})$ & $2.005 .093,6$ & $2.124 .100,7$ & $2.168 .392,0$ \\
\hline BEP harga telur $(\mathbf{R p})$ & $\mathbf{1 5 . 1 4 9 , 2 4}$ & $\mathbf{1 5 . 5 4 5 , 2 1}$ & $\mathbf{1 5 . 4 2 5 , 8 9}$ \\
\hline BEP hasil telur $(\mathbf{k g})$ & $\mathbf{1 . 8 4 3 . 7 4 1 , 7}$ & $\mathbf{1 . 9 8 5 . 6 6 2 , 8}$ & $\mathbf{2 . 0 1 5 . 0 2 2 , 1}$ \\
\hline
\end{tabular}

Sumber: Data primer yang diolah (2017)

Tabel 6 menunjukan bahwa total biaya total selama tahun 2015 - 2017 di Rossa Farm. Harga rata - rata penjualan telur utuh yaitu pada tahun 2015 Rp. 16.475,-, tahun 2016 Rp. 16.629,dan tahun 2017 Rp. 16.600. BEP harga telur utuh pada tahun 2015 adalah Rp. 15.149,24,dengan BEP hasil telur utuhnya adalah $1.843 .741,7 \mathrm{~kg}$, pada tahun 2016 BEP hasil telur utuh yaitu 1.985.662.8 kg dan BEP harga telur utuh yaitu Rp. 15.545,21,-. Sedangkan BEP hasil dan harga untuk tahun 2017 yaitu 2.015.022,1 kg dan Rp. 15.425,89,-.

\section{Margin Of Safety (MOS)}

Dari target penjualan yang telah dianggarkan manajemen memerlukan pula informasi mengenai berapa jumlah maksimum penurunan target penjualan yang boleh terjadi agar perusahaan tidak mengalami kerugian. Margin of safety atau batas keamanan usaha dihitung berdasarkan selisih antara target penjualan yang ditargetkan dengan nilai penjualan pada titik impas. Perusahaan yang memiliki Margin of safety yang besar lebih baik dibandingkan dengan perusahaan yang mempunyai Margin of safety yang rendah, karena Margin of safety menunjukan indikasi atau memberikan gambaran kepada manajemen berapakah penurunan penjualan yang dapat ditolelir sehingga perusahaan tidak menderita rugi tetapi juga belum memperoleh laba (Munawir yang dikutip oleh Candra, 2012).

Tabel 7. Nilai Margin of safety penjualan telur utuh selama tahun $2015-2017$.

\begin{tabular}{|l|r|r|r|}
\hline \multicolumn{1}{|c|}{ Uraian } & \multicolumn{1}{c|}{ Tahun 2015 } & \multicolumn{1}{c|}{ Tahun 2016 } & \multicolumn{1}{c|}{ Tahun 2017 } \\
\hline Penjualan $(\mathrm{kg})$ & $2,005,093.6$ & $2,124,100.7$ & $2,168,392.0$ \\
\hline Penjualan break even $(\mathrm{kg})$ & $1,843,741.7$ & $1,985,662.8$ & $2,015,022.1$ \\
\hline Margin of safety $(\%)$ & $\mathbf{9 . 7 1 \%}$ & $\mathbf{6 . 5 2 \%}$ & $\mathbf{1 0 . 4 1 \%}$ \\
\hline
\end{tabular}

Sumber: Data primer yang diolah (2017) 
Tabel 7 menunjukan bahwa tingkat penjualan telur utuh yang harus dicapai oleh usaha peternakan ayam petelur Rossa Farm yaitu pada tahun 2015 tidak boleh turun lebih dari 9,71\% atau $183.867,8 \mathrm{~kg}$. Pada tahun 2016 tidak boleh turun lebih dari 6,52\% atau 138,491.37 kg, sedangkan untuk tahun 2017 tidak boleh turun lebih dari 10,41\% atau 225,729.61 kg dari penjualan yang direncanakan agar usaha peternakan ayam petelur Rossa Farm tidak menderita rugi tapi juga tidak memperoleh laba.

\section{Analisis Finansial}

Hasil analisis arus kas terhadap usaha peternakan Rossa Farm selama tiga tahun dapat dilihat pada lampiran. Untuk menilai kelayakan usaha peternakan ayam petelur pada Rossa Farm analisa finansial yang digunakan dengan menggunakan kriteria- kriteria penilaian kelayakan yaitu NPV ,IRR.

\section{NPV (Net Present Value)}

Merupakan salah satu kriteria yang banyak digunakan untuk menentukan apakah rencana usaha tersebut layak untuk dilaksanakan atau tidak. Nilai NPV yang diperoleh dari usaha peternakan ayam petelur Rossa Farm pada suku bunga bank atau discount factor sebesar $12 \%$ adalah Rp. 2.14.131.163,9,- atau nilai NPV lebih besar dari 0 maka usaha ayam petelur ini layak untuk dijalankan.

\section{IRR (Internal Rate of Return)}

Merupakan nilai yang menggambarkan tingkat kemampuan suatu usaha atau proyek dalam pengembalian modal pinjaman. Nilai IRR yang diperoleh oleh usaha petenakan Rossa Farm adalah $20,13 \%$ atau lebih dari nilai SOCC (12\%), maka usaha ini layak untuk dijalankan.

\section{KESIMPULAN DAN SARAN}

\section{Kesimpulan}

Berdasarkan hasil analisa ekonomi yang dilakukan untuk menilai kelayakan usaha peternakan ayam petelur Rossa Farm dengan menggunakan sistem closed house, maka dapat diambil kesimpulan bahwa usaha peternakan tersebut layak untuk dikembangkan.

Hal ini berdasarkan nilai IRR yang diperoleh oleh usaha petenakan Rossa Farm adalah 20,13 $\%$ atau lebih dari nilai SOCC (12\%). Serta Nilai NPV yang diperoleh dari usaha peternakan ayam petelur Rossa Farm pada suku bunga bank atau discount factor sebesar $12 \%$ adalah Rp. 2.14.131.163,9,- atau nilai NPV lebih besar dari 0 maka usaha ayam petelur ini layak untuk dijalankan.

\section{Saran}

Saran yang dapat diberikan sebagai hasil dari analisa yang dilakukan terhadap usaha ayam ras petelur Rossa Farm yaitu menyusun proyeksi arus kas untuk menentukan langkah atau tindakan mengenai kelangsungan perkembangan usaha peternakan ayam petelur Rossa Farm di masa yang akan datang. 


\section{DAFTAR PUSTAKA}

Badan Pusat Statistik Indonesia. 2016. "Populasi Ayam Ras Petelur Menurut Provinsi". http://www.bps.go.id/linkTableDinamis/view/id/1013. (Diakses, 1 Januari 2017)

Badan Pusat Statistik Kabupaten Blitar. 2015. Pertanian. Katalog BPS : 11001002.3505. Blitar.

Candra, Simon, U. D. Hari, dan B. Hartono. 2012. “Analisis Ekonomi Usaha Ayam Petelur Cv. Santoso Farm Di Desa Kerjen Kecamatan Srengat Kabupaten Blitar”. Jurnal Fakultas Peternakan Univesitas Brawijaya. Malang.

Dinas Peternakan Provinsi JawaTimur. 2013. Data Statistik. www.disnak.jatim.go.id./web/layananpublik. (Diakses, 1 Januari 2017)

Krisno, R. Dian. 2013. "Kelayakan Usaha Budidaya Ayam Petelur (Analisis Biaya Manfaat Dan BEP Pada Keanu Farm, Kendal)”. Jurnal Universitas Islam Semarang.

Mahyuddin. 2013. "Analisis Pendapatan Usaha Peternakan Ayam Ras Petelur Pada Fase Pemeliharaan Starter Grower Dan Layer Di Kecamatan Mattirobulu Kabupaten Pinrang". Makasar.

Mufida, L. N.2012. Blog.ub.ac.id/nurlailatulmufida/2012/04/14/layer-ayam-petelur-tugasilmu-peternakan-umum/. (Diakses, 1 Januari 2017)

Mustika, N. D. 2011. "Analisis Pendapatan Usaha Peternakan Ayam Petelur Di Kecamatan Takeran Kabupaten Magetan”. Jurnal Universitas Sebelas Maret. Surakarta.

Pratiwi, L. 2014. Analisis Studi Kelayakan Bisnis Pada Jawatop Bakery Di Kelurahan Pasteur, Kecamatan Sukajadi Bandung. Jurnal Universitas Pendidikan Indonesia.

Putra.2008. "Penyusutan Aktiva Tetap (Depreciation)". http://www.putra.blogspot.com. (Diakses, 2 Maret 2013)

Rivkas. 2010. "Kandang Closed House". http://kandang closedhouse.blogspot.co.id/2010/08/kandang-closed-house.html. (Diakses, 1 Januari 2017).

Yupi. 2011.”Analisis Usaha Tani Ayam Ras Petelur". Jurnal Universitas Islam Negeri Syarif Hidayatullah. Jakarta. 